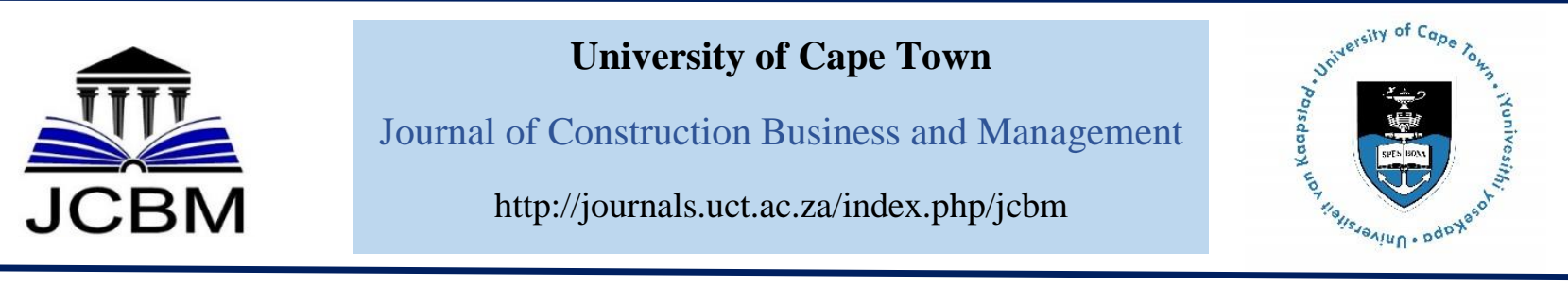

\title{
Frameworks for Material Waste Minimization on Nigerian Building Projects
}

\author{
O. J. Oladiran ${ }^{1}$, O. E. Ogunsanmi ${ }^{2}$ and M. O. Dada ${ }^{3}$ \\ ${ }^{1.2}$ Department of Building, University of Lagos, Nigeria.
}

Received 16 May 2018; received in revised form 27 July 2018; 18 January 2019; accepted 20 January 2019. https://doi.org/10.15641/jcbm.3.1.2019.593

\begin{abstract}
A novel approach to solving waste incidence of materials on building projects is to framework the issues and processes that are involved in its minimization. The objective of the study is to develop and validate frameworks for material waste minimization in building projects. This study is a survey research in South West Nigeria. Define, Review, Identify, Verify and Execute (DRIVE) and Construction Process Improvement Methodology (CPIM) techniques were used to develop the proposed frameworks; while the validation was done by face validity and scoring model approaches. A pilot validation was done by five academics while the main validation involved 17 potential end users. Data were analysed with frequency and percentage. The study reveals that the frameworks are clear, informative, appropriate and applicable. It is concluded that the frameworks can minimize material waste at every stage of building projects. It is therefore recommended that the proposed FMWM should be adopted by all stakeholders to prevent and minimize material waste at all stages of building projects.

Keywords: CPIM, DRIVE, Frameworks, Minimization, Prevention, Waste.
\end{abstract}

\section{Introduction}

A framework is a schematic and interrelated processes, procedures or illustrations to achieve a goal. Material waste minimization requires a systematic arrangement of issues, such as sources and causes of waste, and minimization strategies to foster its attainment in building projects. Lu and Yuan (2011) indicate that although considerable researches have been carried out on waste management, little effort have been made in embracing all issues of waste management in form of framework. The study therefore developed an intuitive framework, not to minimize material wastage, but to understand the state of the art of the waste management studies in several journals. Dajadian and Koch (2014) also opine that construction waste potents financial and environmental problems for construction industry, which has drawn serious attention from all stakeholders globally. This has made a lot of countries to promulgate regulations geared toward minimization of waste, such as United Nations Framework Convention on Climate Change (UNFCCC), Ontario 3R Regulations (Recycling Council of Ontario (RCO), 2009), National Solid Waste Management Policy (NSWP) in Malaysia and so on. In the case of Nigeria, there are frameworks for several aspects of construction management, such as the framework for managing risk in privately financed markets projects (Awodele, 2012); but there is no framework or regulations for the minimization of material wastages in building projects. This study therefore endeavours to fill this gap, by developing and validating frameworks for the minimization of material waste on building projects in Nigeria. Building project stages in this study include client (i.e. clients' direct involvement stage), design, purchase/supply, handling and operation. Thus, the specific objective of the study is to develop and validate frameworks to minimize material waste at these five identified stages in the building projects of medium and large contractors. The problem that the study seeks to solve to minimize material wastages on construction projects through the instrumentality of frameworks. The frameworks are all encompassing and thus will be veritable tools for designers, contractors and project managers to procure projects at minimal waste generation. They will also be useful to public clients, project managers and waste managers.

\section{Literature Review}

\subsection{Types and causes of material waste}

\footnotetext{
${ }^{1}$ Corresponding Author.

Email address: ooladiran@ unilag.edu.ng
} 
Skoyles and Skoyles (1987) identify two types of construction waste, namely: structure and finishing waste. Material waste generated during the builder's work stage are termed structure waste such as concrete pieces, reinforcement and timber off-cuts, broken blocks and bricks, filtered nails and so on. Finishing wastes are those generated at the finishing stage, these include among others broken tiles and glass, smeared paints, excessive cement mortar, aluminium profiles, off-cuts of ceiling and wall finishes, packaging of public and household facilities such as gas cookers, bathtubs, washtubs, window frames and so on. Skoyles and Skoyles (1987) further group building material waste into direct and indirect waste. Direct waste is the loss of those materials which are damaged and cannot be repaired and subsequently used, or which are lost during the building process. Indirect waste is distinguished from direct waste because it normally represents only a monetary loss and the materials are not lost physically. Construction material waste can also be classified into unavoidable waste (or natural waste), in which the investment necessary for its reduction is higher than the economic benefit produced; and avoidable waste, when the cost of waste is significantly higher than the cost of preventing it. Avoidable waste is related to the level of technological development and hence the rate varies from companies to companies (Formoso, Isatto \& Hirota, 1999).

Akinkurolere and Franklin (2005) revealed the sources of materials waste in South West Nigeria as storage system, transport and delivery to site, intrasite/transit, wrong specification, fixing, negligence, pilfering and theft, conversion, demolition, mismanagement of materials, wrong use, residual waste, over estimation and unskillful labourers. In the same vein, Wahab and Lawal (2011) identified over consumption of resources as the most occurred cause of material waste on other projects in South West Nigeria. This is followed in descending order by composite and the design of building, weather and inappropriate storage, mishandling or careless delivery, vandalism, rework/improve, lack of recording of materials supplied and used on site, and site office waste. Other causes identified in Wahab and Lawal (2011) include usage of wet-trade process instead of prefabricated elements and non-calculation of waste index. In another region of Nigeria, Adewuyi and Otali (2013) revealed 74 causes of waste generation in SouthSouth Nigeria, out of which rework contrary to drawings and specifications is topmost and the least are inappropriate equipment and difficulties in obtaining work permits. Other causes in the study comprise design changes and revisions, waste from uneconomical shapes, severe weather conditions, purchase of materials contrary to specifications, using untrained labours, lack of on-site control, use of incorrect materials, overproduction, over ordering or under ordering, substitution of a material by a more expensive one, rework, poor workmanship, errors in contract documents, purchase of material contrary to specification, inadequate supervision and so on. The contractors and consultants considered all the 74 causes important in contributing to waste generation, but their degree of importance or contribution to waste generation varies.

\subsection{Materials Waste Minimization}

Li, Zhang, Ding and Feng (2015) posit that estimation of materials waste is sequel to its successful minimization for sustainable environment. In this regard, Dajadian and Koch (2014) highlight certain waste models to be used for waste estimation, which include average cost estimation model (ratio of total cost of waste with the total production for a period), equivalent method of cost estimation and activity-based costing model. Dajadian and Koch (2014) also posit that waste can be minimized by investment in waste management, on-site waste management or treatment locations, waste contractors, designing out waste, using the $3 \mathrm{R}$ 's, prefabrication and Industrialized Building Systems (IBS). Investment in waste management is through assigning workers responsible for on-site waste collection, sorting and handling, purchasing equipment and machines for waste management, developing and implementing waste management plans, motivating practitioners to minimize waste and improving operatives' skills of waste handling through vocational training. On-site waste management location is required for collection and sorting to minimize waste on sites. Waste contractors are responsible for removal of waste from sites, after the waste have been collected in labeled bins according to the waste stream. Dajadian and Koch (2014) recommended having subcontractor solely meant for managing waste on a project. The waste contractor will estimate waste quantity and component in addition to periodic meeting to discuss waste. Designing out waste is designers' attempt to avoid, eliminate and reduce waste at sources. This is achievable via steel formworks; use of prefabrication and off-site prefabrication; standard component; realistic component size, capacity and specification; minimizing temporary works; optimizing design lives; specification of recycled materials in design; designing for recycling and ease of disassembly; identification of materials/products which create waste; and communication. This strategy offers the greatest opportunities for waste minimization.

Poon, Yu, Wong and Cheung (2004) note that design is the initial stage of the project that material control can be exerted to reduce large number of off-cuts during construction (Proverbs and Olomolaiye 1995; Otunola, 2004). Poon et al. (2004) observe that clients' requirements, cost effectiveness and aesthetics are factors that hinder designers from designing out waste on projects. According to Ekanayake and Ofori, (2000, 2004), and Enshassi (1996), improper designs are responsible for much of material waste on site. Akande (2000) notes that achieving minimum waste was never a priority in design in Nigeria. In the realization of this, Ekanayake and Ofori developed a Building Waste Assessment Score (BWAS) model for designers to design buildings of minimum waste generation on site. It serves as a basis to evaluate design on waste. However, the model is incomplete because it does not incorporate foundation, and mechanical and electrical (M and $\mathrm{E}$ ) engineering works. Furthermore, Fuchs (2003) corroborated by CRiBE (2003) offers several ideas to design-out waste in construction. The $3 \mathrm{Rs}$ connote reduce, reuse and recycle. Tam and Tam (1994) posit that reuse, recycle and reduce are the only methods to recover waste generated, but they require coordination among 
designers and constructors. Ng, Seow and Goh (2015) opine that weaknesses in the implementation on solid waste reduction through $3 \mathrm{R}$ among contractors in the construction industry will cause unsustainable construction waste management. Thus, Construction waste should be managed through the $3 R$ as it is sustainable.

$\mathrm{Ng}$ et. al. (2015) indicate that the $3 \mathrm{R}$ practice is prevalent among contractors in Penang, but the percentage of construction waste that is managed through $3 \mathrm{R}$ practice is still very low. This is because contractors only reuse and recycle common materials like steel and wood, which make up very little of the overall amount of construction waste. The study recommends concerted efforts of all parties involved, in form of top-down approach, to overcome the challenges and practice $3 \mathrm{R}$ to reduce construction waste disposal in landfills. Top-down approach is a style of autocratic and hierarchical decisionmaking, where organizational and leadership changes in the strategy or plan are established from the top and passed down to the lower level for implementation. Government is to also enforce implementation of laws and policies to mandate contractors to implement $3 \mathrm{R}$, via monitoring, guidelines, standards, incentives and penalties. Relevant bodies can also organize talks, courses, awareness campaigns, and education and training programs among contractors, in addition to the use of technology, to disseminate information and knowledge about $3 \mathrm{R}$ and to motivate the contractors to practice $3 \mathrm{R}$. Reduce is the most effective and efficient because the cost of waste transportation and disposal are also reduced. Reusing materials reduces landfill disposal and saves cost. RCO (2009) opines that some of the wastes generated on sites have secondary market value, indicating that it is less costly to reuse them than disposal. Recycling protects the environment, thus, the Ontario 3Rs Regulations stipulates that new construction should have a definite program and efforts for reusing and recycling waste (RCO, 2009). Edwards (1999) states that the benefits of recycling include reducing the demand upon new resources; cutting down on transport and production energy costs; and using waste which would otherwise be lost to landfill sites. Manowong and Brockmann (nd) estimate that energy saving from recycling all construction waste could be 3 , $553 \mathrm{kWh}$ per year in Thailand. Although, some construction waste such as wood, plastic, paper and metal are used for recycling but a larger part such as concrete, cement, and bricks are sent to landfills because of lower cost and greater convenience. Tam and Tam (2006) reveal that recycling can increase contractors' competitiveness through lower production costs and a better public image. The study therefore proposes measures to improve recycling, comprising higher landfill charges, centralized recycling centre, governmental provision land for recycling plants, innovative demolition methods, locations to drop-off recyclable materials, flexible demolition periods, mobile recycling plants, reusable components, higher flexibility in receiving concrete waste in recycling plant, and balancing the supply and demand of recycled materials through legislations or incentive schemes.

Additional strategies to minimize material wastages that are apparent in previous works include waste management plan (Oladiran, 2008a; Poon et. al., 2004); waste handling methods (Motete, Mbachu \& Nkado, 2003; Seydel, Wilson \& Skitmore, 2002); good material ordering and storage (Ekanayake \& Ofori, 2000); subcontractor's responsibility (Proverbs \& Olomolaiye, 1995) among others. This present study employs the sources and causes of materials waste indicated in this review, with all these strategies to develop and validate frameworks to minimize material waste in construction projects.

\section{Research Method}

\subsection{Questionnaire Survey}

An initial questionnaire survey was conducted in the study area, which was the entire South West Nigeria. The population of the study is spread across the South West, which consists of six states- Lagos, Ogun, Oyo, Osun, Ondo and Ekiti. The population for this study is the site managers of building projects under execution by medium and large contracting organizations in South West Nigeria. The projects used for the study were identified in the research area based on the specified requirements, since there is no list of such projects. A total of 167 building projects under execution by medium and large contracting organizations were identified and selected as sample in the research area through purposive sampling technique. A questionnaire was designed to elicit information from the site managers comprising three sections, namely, respondents' and organizations' general information (see Table 1); examination of the occurrence, impact and severity of 55 causes of material waste (severity was calculated as the product of occurrence and impact of each causes); and evaluation of the usage and effect of 40 minimization strategies. The questionnaire data were analyzed using mean, frequency, rank, and the result is presented in Table 2 .

1: Project' organizations' and site managers' profile

\begin{tabular}{|c|c|c|}
\hline \multicolumn{3}{|c|}{ Project Organizations. } \\
\hline & Type & Percentage \\
\hline & Indigenous & 74 \\
\hline & Multinational & 26 \\
\hline \multirow{5}{*}{ Age } & $0-5$ years & 8 \\
\hline & $6-10$ years & 21 \\
\hline & $11-15$ years & 31 \\
\hline & $16-20$ years & 13 \\
\hline & Above 20 years & 27 \\
\hline \multirow{2}{*}{ Staff Strength } & $8-114$ & 90 \\
\hline & Above 114 & 10 \\
\hline \multirow{4}{*}{ Structure } & Project & 28 \\
\hline & Matrix & 23 \\
\hline & Functional & 28 \\
\hline & Mixed & 21 \\
\hline & Site Managers & \\
\hline \multirow{4}{*}{ Profession } & Architecture & 13 \\
\hline & Building & 32 \\
\hline & $\begin{array}{l}\text { Civil } \\
\text { Engineering }\end{array}$ & 37 \\
\hline & $\begin{array}{l}\text { Quantity } \\
\text { Surveying }\end{array}$ & 18 \\
\hline Academic & OND & 2 \\
\hline Qualification & HND & 24 \\
\hline
\end{tabular}




\begin{tabular}{|c|c|c|}
\hline & B.Sc & 37 \\
\hline & M.Sc & 35 \\
\hline & PGD & 1 \\
\hline & $\mathrm{PhD}$ & 1 \\
\hline \multirow{5}{*}{ Experience } & $0-5$ years & 18 \\
\hline & $6-10$ years & 49 \\
\hline & $11-15$ years & 16 \\
\hline & $16-20$ years & 13 \\
\hline & Above 20 years & 4 \\
\hline \multirow{6}{*}{ Professional Body } & NIOB & 33 \\
\hline & NIQS & 14 \\
\hline & NIA & 16 \\
\hline & NSE & 28 \\
\hline & NATE & 8 \\
\hline & ACEN & 1 \\
\hline \multirow{5}{*}{$\begin{array}{l}\text { Grade of } \\
\text { Membership }\end{array}$} & None & 6 \\
\hline & Associates & 25 \\
\hline & Graduates & 49 \\
\hline & Corporate & 16 \\
\hline & Fellow & 4 \\
\hline
\end{tabular}

Key: OND : Ordinary National Diploma, HND: Higher National Diploma, PGD: Post Graduate Diploma, NIOB: Nigerian Institute of Building, NIQS: Nigerian Institute of Quantity Surveying, NIA: Nigerian Institute of Architects, NSE: Nigerian Society of Engineers, NATE: Nigerian Association of
Technologists in Engineering and ACEN: Association of Consulting Engineers in Nigeria

\subsection{Development of the Proposed Frameworks for Material Waste Minimization (FMWM).}

Problem solving methodologies are used to investigate issues by probing into existing structures and identifying areas of rectification and improvement (Straker, 1995). Define, Review, Identify, Verify and Execute (DRIVE) and Construction Process Improvement Methodology (CPIM) techniques are two of such methodologies that were used in this study to develop the proposed framework for material waste minimization (FMWM) of medium and large building projects. CPIM centers on improvement of construction process and waste reduction. The two techniques were used to set up and propose the FMWM logically and sequentially, in line with construction stages' category, based on the finding of the questionnaire survey presented in Table 2 . The content of the frameworks, that is, causes, sources and minimization strategies of material waste were coined from literature and Table 2. The layout was constructed in line with the sequence of project stages reflected in Table 2 . The research also explored a potential implementation strategy of the proposed frameworks.

Table 2: Severity of the causes of material waste.

\begin{tabular}{|c|c|c|c|c|c|c|}
\hline SN & Causes of Materials Waste & $\begin{array}{c}\text { Mean of } \\
\text { Frequency }\end{array}$ & $\begin{array}{l}\text { Mean of } \\
\text { Impact }\end{array}$ & Severity(S) & $\mathbf{R}$ & OR \\
\hline & Client Source. & 2.93 & 3.48 & 10.21 & & 1 \\
\hline 1 & Undue pressure to deliver & 2.99 & 3.47 & 10.38 & 1 & 4 \\
\hline 2 & Expectations of too high standard & 2.99 & 3.45 & 10.32 & 2 & 5 \\
\hline 3 & Delay decisions /changes & 2.91 & 3.51 & 10.21 & 3 & 7 \\
\hline \multirow[t]{2}{*}{4} & Undue interference with project's execution & 2.84 & 3.49 & 9.91 & 4 & 9 \\
\hline & Design Source & 2.75 & 3.38 & 9.27 & & 2 \\
\hline 1 & Design changes and revisions & 3.34 & 3.9 & 13.03 & 1 & 1 \\
\hline 2 & Lack of collaboration & 3.24 & 3.51 & 11.37 & 2 & 2 \\
\hline 3 & Materials and component complexity & 3.05 & 3.47 & 10.58 & 3 & \\
\hline 4 & Lack of or error in information on types and sizes of materials & 2.83 & 3.61 & 10.22 & 4 & 6 \\
\hline 5 & Over Designing & 2.74 & 3.51 & 9.62 & 5 & 11 \\
\hline 6 & Specifying materials' without considering standard sizes. & 2.80 & 3.33 & 9.32 & 6 & 14 \\
\hline 7 & Lack of Contractors' influence & 2.71 & 3.41 & 9.24 & 7 & 15 \\
\hline 8 & Design Coordination & 2.76 & 3.34 & 9.22 & 8 & 16 \\
\hline 9 & Ineffective Communication & 2.75 & 3.26 & 8.97 & 9 & 18 \\
\hline 10 & Delay in approval of drawings & 2.58 & 3.20 & 8.26 & 10 & 25 \\
\hline 11 & Unfamiliarity with alternative Products & 2.61 & 3.13 & 8.17 & 11 & 27 \\
\hline 12 & Incorrect/Inconclusive standard specification & 2.48 & 3.29 & 8.16 & 12 & 28 \\
\hline 13 & Uncompleted Design & 2.50 & 3.23 & 8.08 & 13 & 29 \\
\hline 14 & Poor site documentation & 2.43 & 3.26 & 7.92 & 14 & 32 \\
\hline \multirow[t]{2}{*}{15} & Designers' Inexperience & 2.37 & 3.20 & 7.58 & 15 & 41 \\
\hline & Handling Source. & 2.52 & 3.38 & 8.51 & & 3 \\
\hline 1 & Unpacked supply i.e. loosed materials & 2.81 & 3.61 & 10.14 & 1 & 8 \\
\hline 2 & Throwaway packaging & 2.80 & 3.53 & 9.88 & 2 & 10 \\
\hline 3 & Poor site storage & 2.50 & 3.49 & 8.73 & 3 & 21 \\
\hline 4 & Double handling & 2.46 & 3.41 & 8.39 & 4 & 22 \\
\hline 5 & Too much material inventories & 2.48 & 3.30 & 8.18 & 5 & 26 \\
\hline
\end{tabular}




\begin{tabular}{|c|c|c|c|c|c|c|}
\hline 6 & Imperfect planning of construction & 2.41 & 3.28 & 7.90 & 6 & 33 \\
\hline 7 & Wrong equipment for materials' movement. & 2.34 & 3.30 & 7.72 & 7 & 40 \\
\hline \multirow[t]{2}{*}{8} & Unfriendly attitudes from personnel & 2.35 & 3.11 & 7.31 & 8 & 47 \\
\hline & Purchase/Supply Source. & 2.48 & 3.28 & 8.14 & & 4 \\
\hline 1 & Delay in materials supply & 2.65 & 3.38 & 8.96 & 1 & 10 \\
\hline 2 & Damage during transportation & 2.60 & 3.44 & 8.94 & 2 & 20 \\
\hline 3 & Ordering that do not fulfill design & 2.42 & 3.42 & 8.28 & 3 & 24 \\
\hline 4 & Lack of possibilities to order small quantities. & 2.55 & 3.12 & 7.96 & 4 & 31 \\
\hline 5 & Delay in transportation and installation of equipment & 2.46 & 3.19 & 7.85 & 5 & 36 \\
\hline 6 & Lack of coordination & 2.39 & 3.26 & 7.79 & 6 & 38 \\
\hline \multirow[t]{2}{*}{7} & Wrong ordering by Estimators. & 2.32 & 3.14 & 7.28 & 7 & 48 \\
\hline & Operation Source. & 2.43 & 3.14 & 7.62 & & 5 \\
\hline 1 & Inclement weather & 2.85 & 3.37 & 9.60 & 1 & 12 \\
\hline 2 & Workers mistake & 2.65 & 3.40 & 9.01 & 2 & 17 \\
\hline 3 & Poor Workmanship & 2.53 & 3.28 & 8.30 & 3 & 23 \\
\hline 4 & Equipment malfunction shortage. & 2.47 & 3.27 & 8.08 & 4 & 29 \\
\hline 5 & Inappropriate /Misuse of materials & 2.47 & 3.2 & 7.90 & 5 & 33 \\
\hline 6 & Damage caused by subsequent trades. & 2.48 & 3.18 & 7.89 & 6 & 35 \\
\hline 7 & Too much over time for labour & 2.55 & 3.06 & 7.80 & 7 & 37 \\
\hline 8 & Late information & 2.48 & 3.14 & 7.79 & 8 & 38 \\
\hline 9 & Poor formwork & 2.42 & 3.14 & 7.60 & 9 & 12 \\
\hline 10 & Improper planning and organization. & 2.45 & 3.09 & 7.57 & 10 & 42 \\
\hline 11 & Improper sites record & 2.38 & 3.18 & 7.57 & 10 & 42 \\
\hline 12 & Inexperienced inspectors & 2.41 & 3.13 & 7.54 & 12 & 44 \\
\hline 13 & Poor material management practices & 2.36 & 3.17 & 7.48 & 13 & 45 \\
\hline 14 & Lack of subcontractor's skills & 2.40 & 3.07 & 7.37 & 14 & 46 \\
\hline 15 & Lack of supervision and skillful tradesmen & 2.31 & 3.14 & 7.25 & 15 & 9 \\
\hline 16 & Misinterpretation of drawings & 2.29 & 3.16 & 7.24 & 16 & 50 \\
\hline 17 & Accidents & 2.36 & 3.06 & 7.22 & 17 & 51 \\
\hline 18 & Wrong construction methodology & 2.27 & 3.16 & 7.17 & 18 & 52 \\
\hline 19 & Replacement occasioned by wrong materials & 2.34 & 3.03 & 7.09 & 19 & 53 \\
\hline 20 & Poor site layout and setting out & 2.31 & 2.95 & 6.81 & 20 & 54 \\
\hline 21 & Unnecessary people move & 2.18 & 2.74 & 5.97 & 21 & 55 \\
\hline
\end{tabular}

OR= overall rank; $R=$ group rank; $S=$ severity, calculated as the product of frequency and impact, also indexed as: "not sever" from 0.00 - 3.99; "low severity" from 4.00 - 8.99; "medium severity" from 9.00 - 25.00; "high severity" from above 25.00.

\subsection{Validation and evaluation of proposed FMWM}

A combination of face validity approach and scoring model approach was adopted in this study to validate and evaluate the proposed FMWM. Having chosen the approach, certain steps must be followed to ensure that the framework achieve its purpose (Chew \& Sullivan, 2000). The first step is to identify the potential end users who will be involved in carrying out the validation and evaluation exercise. The following were the users identified: I. Indigenous contractors. II. Multinational contractors. III. Public organizations. IV. Consulting organizations. V. Client organizations. The second step is how to go about the exercise. Five academics modified the framework before proceeding to the real validation exercise by the identified users.

\section{Results and discussions}

\subsection{The proposed FMWM for projects of medium} and large contractors
The proposed FMWM pinpoints waste origins and waste routes with efforts to identify their respective waste minimization strategies. It is noteworthy that the proposed FMWM is applicable at every stage of building projects of medium and large organizations - preconstruction stage (i.e. client and design) and construction stage (purchase/supply, handling and operation).

\subsection{Structure of the Proposed FMWM}

The layout of the proposed FMWM is presented in Figure 1. The structure of the proposed frameworks entails two aspects:

1. FMWM levels: These comprise the main-level and subsidiary-level.

The main level outlays an overview of waste origin from all stages of building project and their waste minimization process. The subsidiary-levels comprise five components that are linked to the main-level. 
2. FMWM axis: Horizontal and vertical axes representing waste origin from all stages of building project and waste minimization process respectively. The waste minimization process consists of three stages for both the main and subsidiary-levels (i.e. waste causes' identification; waste analysis and evaluation; and strategies for minimization).

The layout was constructed in line with the sequence of building project stages

\subsection{Main-Level FMWM}

The main-level FMWM shows waste origin from all stages of building project and waste minimization process as shown in Figure 2. The horizontal axis of the mainlevel FMWM comprises sources of waste from the five stages of building project, namely: client, design, purchase/supply, handling and operation. The vertical axis of the framework denotes the waste minimization process, which consists of three stages: identification of severe causes of waste; waste analysis and evaluation; and strategies for minimization. The main-level FMWM contents also link the sub-origins for each of the five sources of waste clusters and their respective strategies for minimization. The contents presented in the main-level are further elaborated within five subsidiary-level components.

\subsection{Subsidiary-Level FMWM.}

Each of the five low-level FMWM components presented in Figures 3,4,5,6 and 7 represents one source of waste from the five stages of building projects, namely: Figure 3: Client waste origin; Figure 4: Design waste origin; Figure 5: Purchase/supply waste origin; Figure 6: Handling waste origin; Figure 7: Operation waste origin.

The subsidiary components adopt the same structure of the main-level in terms of horizontal axis and vertical axis. All the subsidiary components and their contents emanate from Table 2. For instance, one of the client waste origin is "undue pressure to deliver" as shown in Figure 3. Table 2 reveals that undue pressure to deliver from clients is one of the most severe causes of waste on building projects (i.e. origin of waste). This occurs (i.e. the route) as a result of "prioritized targets" and "time constraints" according to experts' opinion. Therefore, the proposed strategies for minimization of "undue pressure" are "setting of good and reasonable targets" and "adequate project duration". This approach was employed to determine potential minimization strategies for each of the sub-waste origins listed in the "routes to waste origins" of all the subsidiary FMWM components.

It is very important to note that, the proposed FMWM suggests that, in addition to several lean construction techniques that have been included and explained in it already, more relevant lean construction techniques should be investigated and embedded as the need arise in all the five subsidiary components to minimize material waste. It is also noteworthy that the proposed FMWM suggests "waste analysis and evaluation" for purchase/supply, handling, operation waste origins, and also "design analysis and assessment for waste" for designs before the application of all the proposed minimization strategies. This is in accordance with the opinion that waste quantity and waste stream should be known before attempting to minimize it (Al-Moghany, 2007).

\subsubsection{Client FMWM}

The origin of material waste from client include undue pressure to deliver, expectation of too high standard, delay decision or changes and undue interference with projects' execution. This is presented in Figure 3.

Undue pressure: it occurs due to prioritized targets and time constraints. Therefore, good targets and adequate project duration were proposed as strategies to minimize them.

Expectation of too high standards: it occurs due to ignorance and unreasonable requirement of clients. Enlightenment of clients and setting of achievable objectives by the clients were proposed as strategies to minimize its occurrence. Delays: it occurs due to financial constraints; while realistic budget and cash flow was proposed as the strategy for minimizing its occurrence. Undue interference: it occurs due to late changes; while avoidance of late changes and project definition were proposed as the minimization strategies

\subsubsection{Design FMWM}

The origins of material waste from design include design changes, lack of collaboration, delay in approval of drawings, lack of standardization and others. This is presented in Figure 4.

Design changes: it occurs due to overdesign, lack of contractors' influence at design stages, non-coordination of designs, incorrect specification, designers' inexperience and site conditions. As a result, the framework proposes flexible design, collaborative design, experienced designers and site visits as strategies for minimization.

Lack of collaboration: it stems from ineffective communication, procurement method and nature of construction industry. The strategies proposed to minimize its occurrence are appropriate construction procurement, collaborative design, effective communication and reengineering.

Delay of approval of drawings: it is caused by incomplete designs, and poor site information and documentation. The strategies to handle them are timely designs and good documentation.

Lack of standardization: it occurs due to specifying materials without considering standard sizes, materials' and components' complexity, incorrect information about materials, unfamiliarity with alternative products and lack of code requirements for standard sizes. The corresponding proposed minimization strategies are designers' familiarity with and specification of standard sizes; inclusion of standard sizes in codes' requirement; compliance to codes' requirements; compatible design; and set-based design.

Others: design waste also originates from not incorporating recycling and reusage; and unnecessary temporary works. The proposed minimization strategies are concurrent design, designing for future, specifying recyclable and reusable materials and components; and elimination of unnecessary temporary works. 


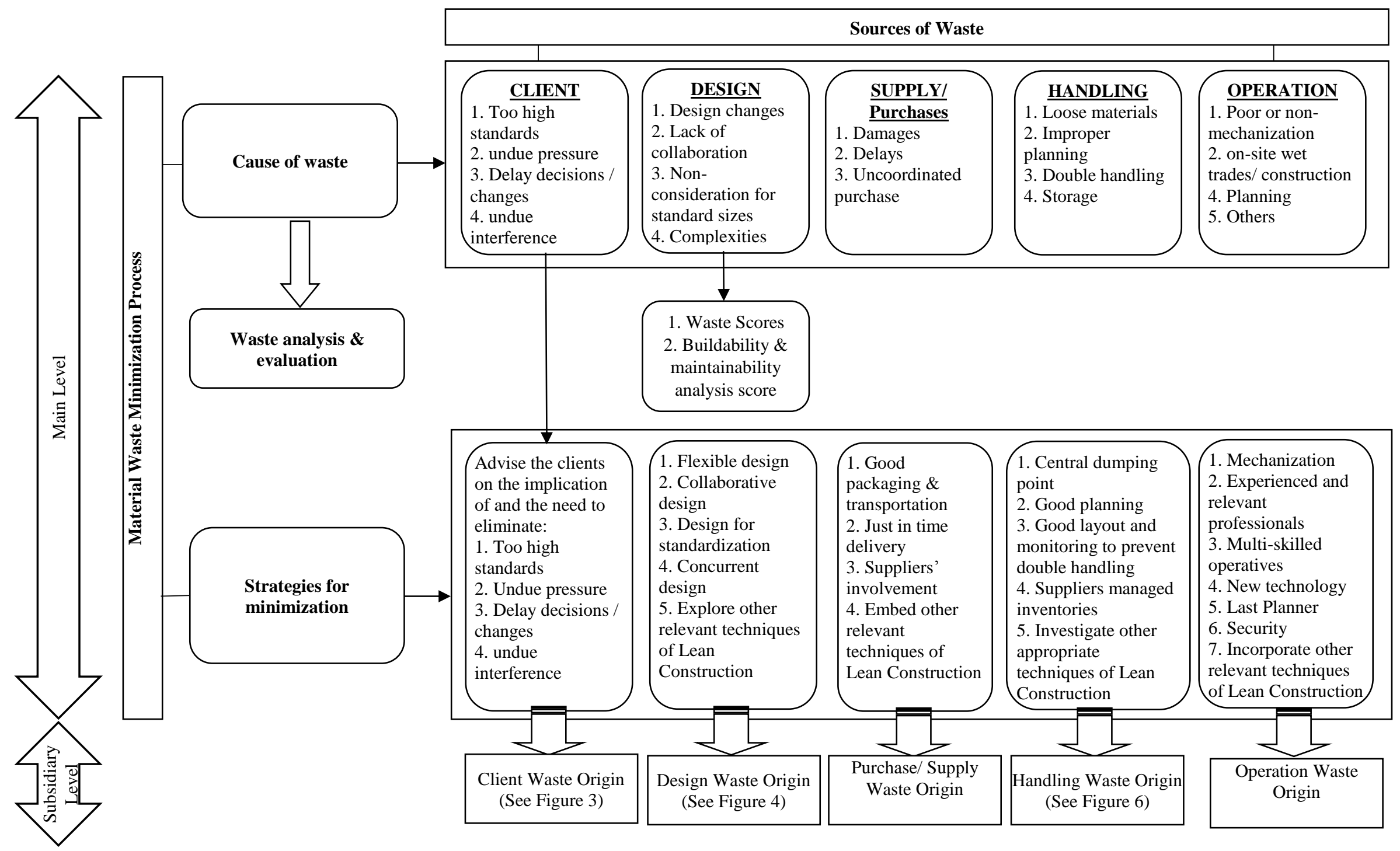

Figure 1: The link between main-level and subsidiary level of materials waste minimization framework for medium and large contracting organizations projects. 


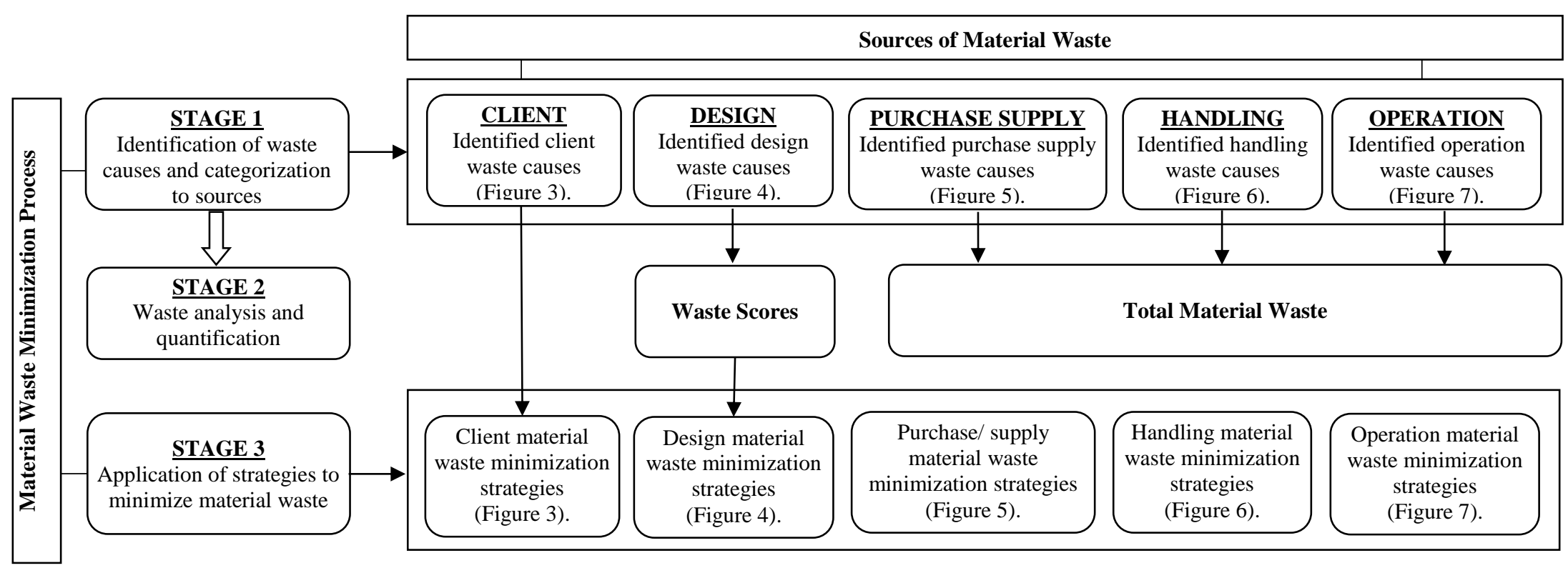

Figure 2: Framework for material waste minimization for medium and large contractors (main-level).

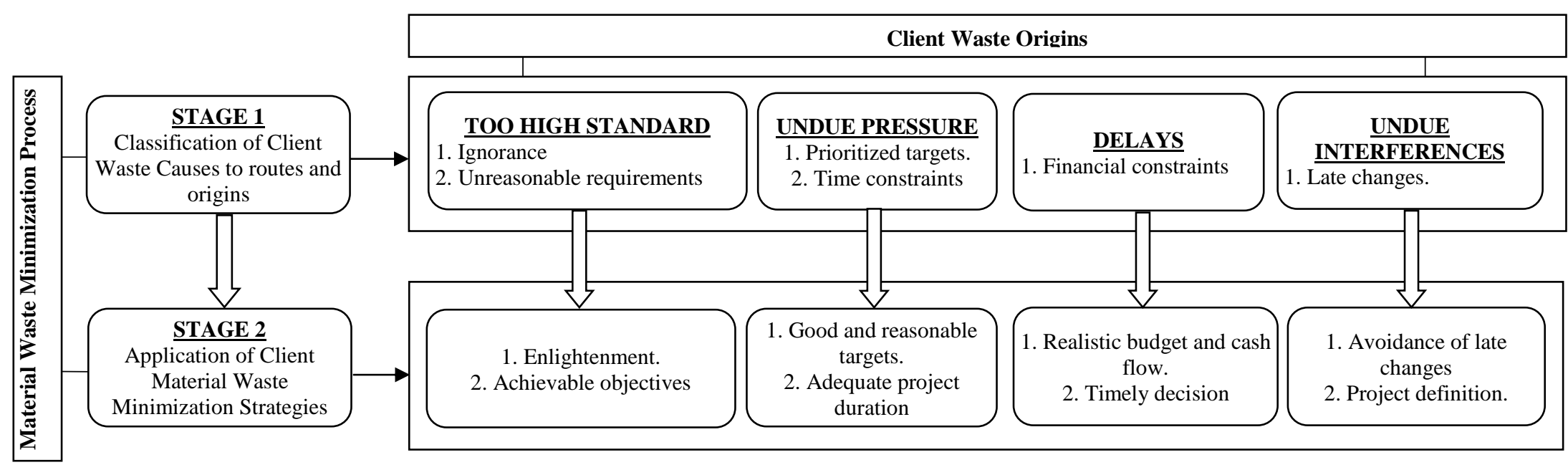

Figure 3: Client waste minimization subsidiary-level framework for medium and large contracting organizations projects. 


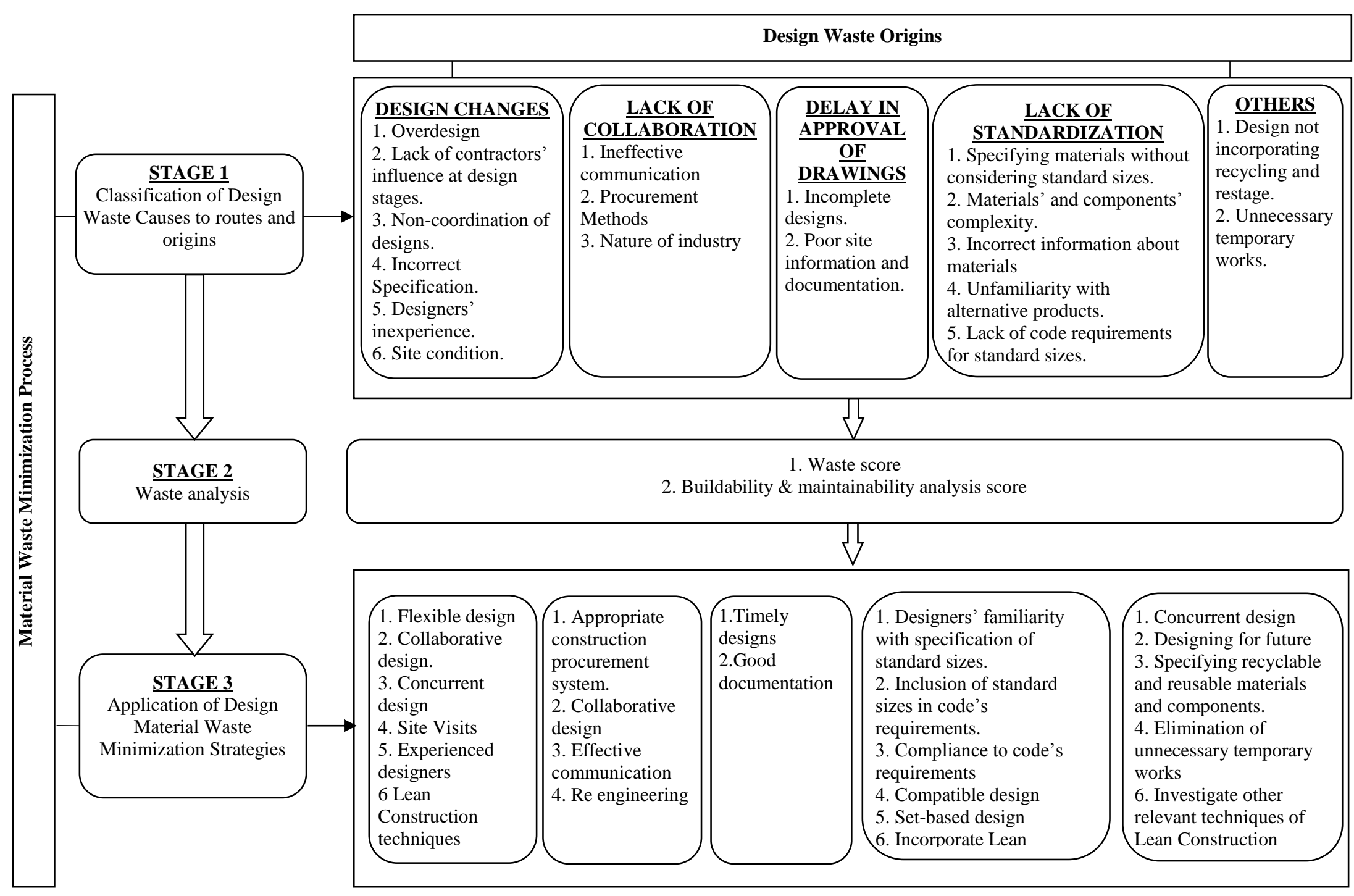

Figure 4: Design waste minimization subsidiary-level framework for medium and large contracting organizations projects. 


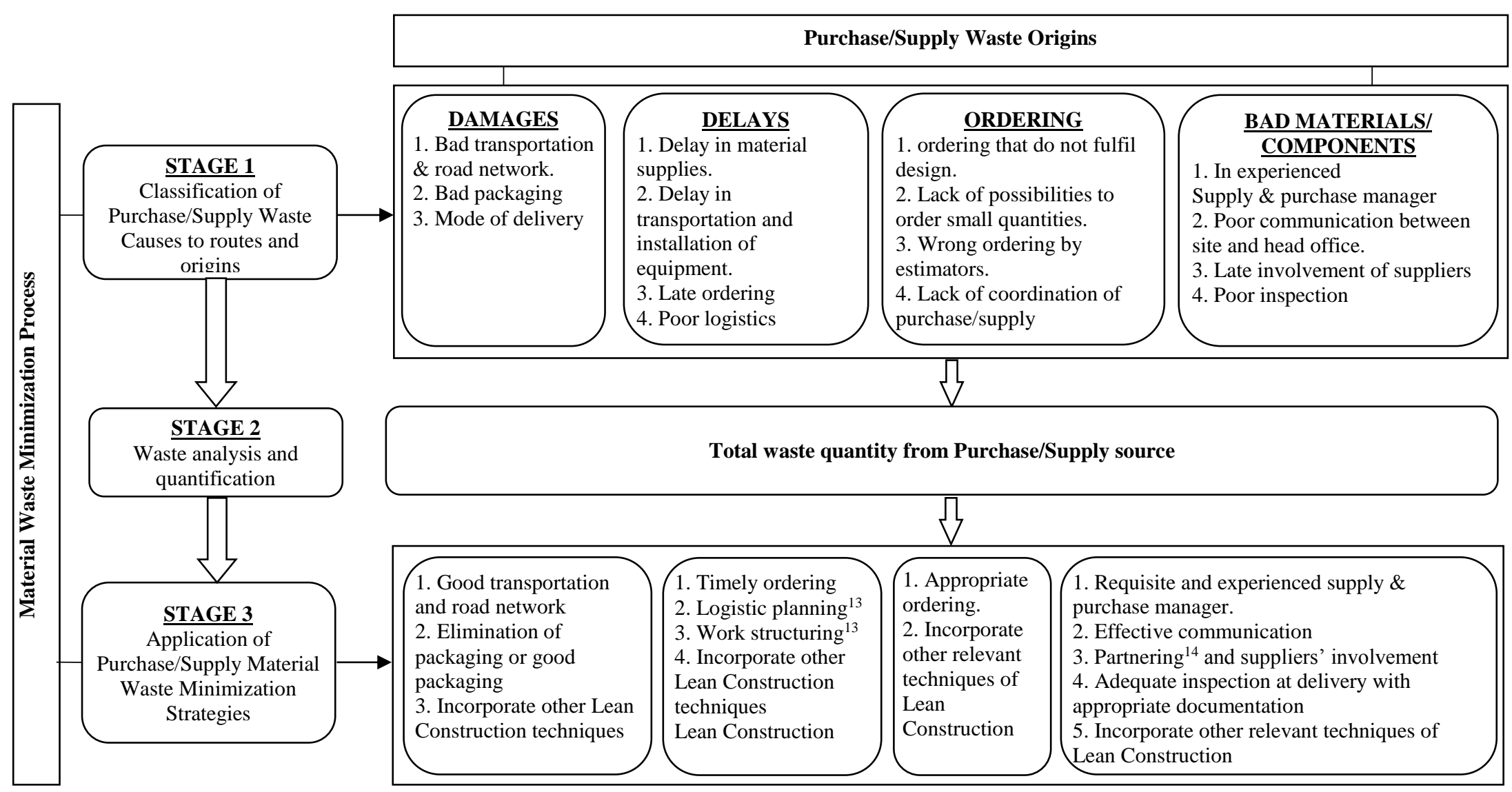

Figure 5: Purchase/Supply waste minimization subsidiary-level framework for medium and large contracting organizations projects 


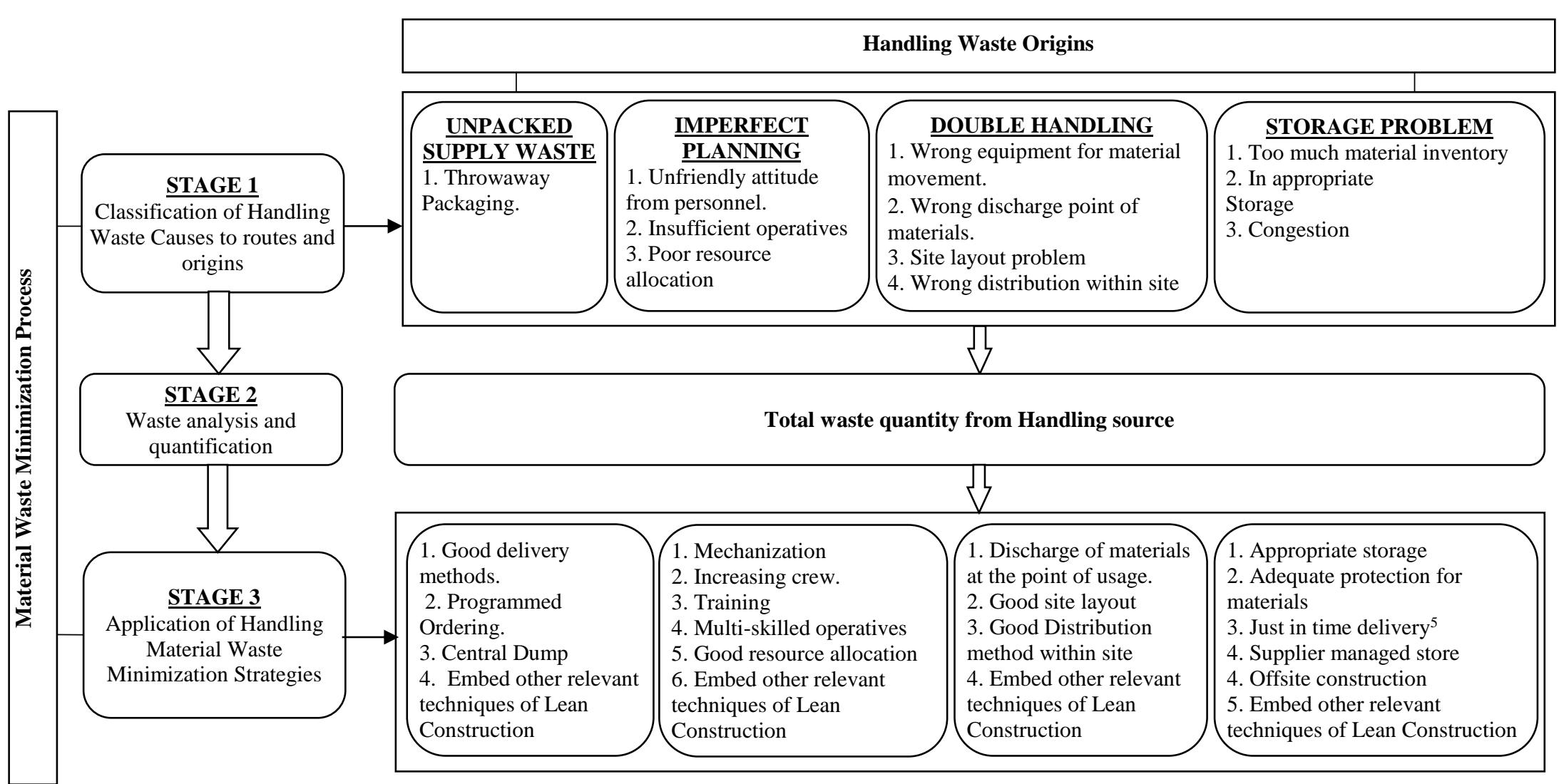

Figure 6: Handling waste minimization subsidiary-level framework for medium and large contracting organizations projects 


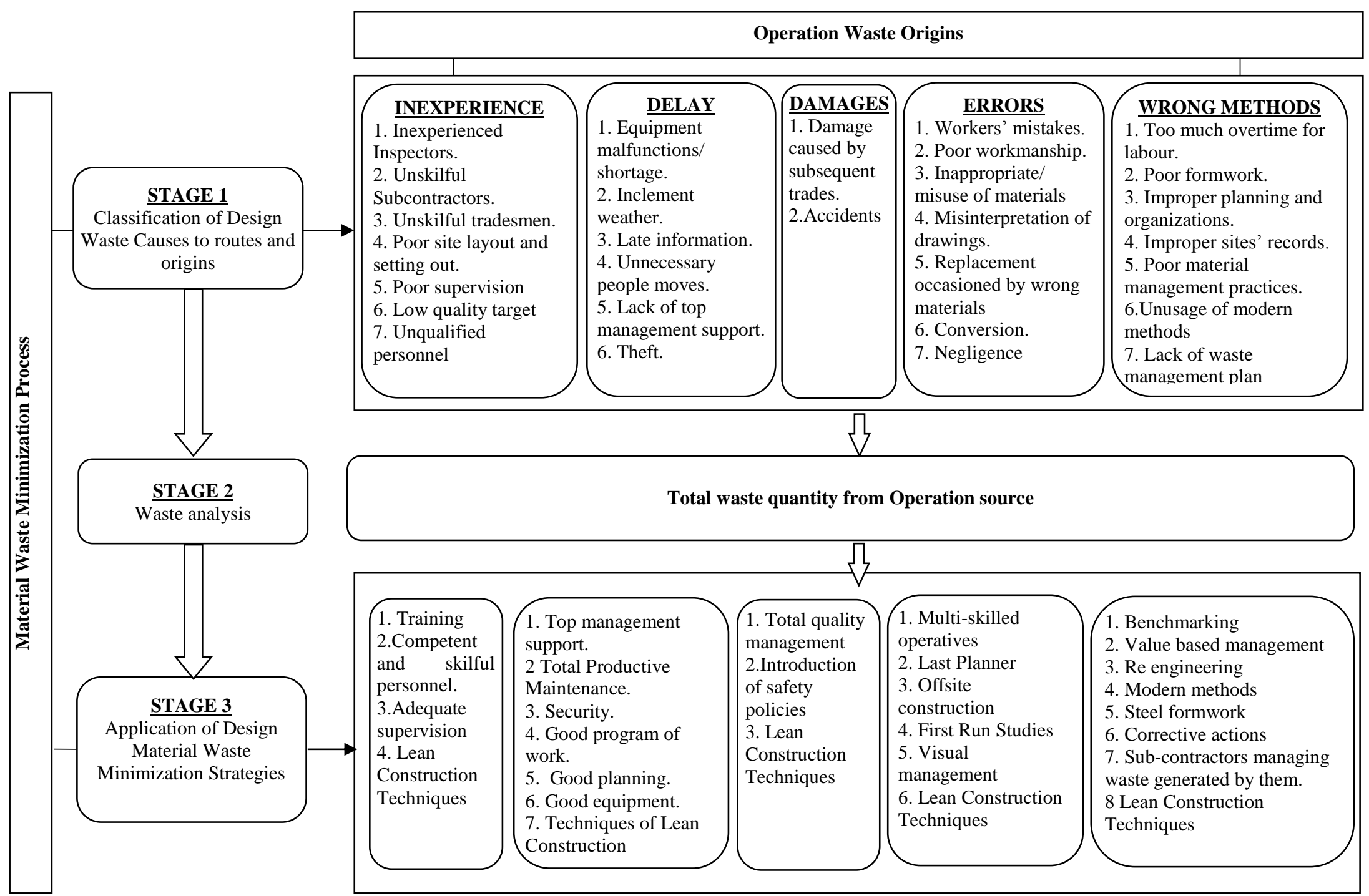

Figure 7: Operation waste minimization subsidiary-level framework for medium and large contracting organizations projects 


\subsubsection{Purchase/Supply FMWM}

The origins of waste from purchase/supply are presented in Figure 5, which include damages, delays, bad materials or products and ordering problems.

Damages: it occurs due to bad transportation and road network, bad packaging and mode of delivery. The proposed minimization strategies consist of good transportation and road network; and elimination of packaging or good packaging. Delays: it occurs due to delay in material supplies, delay in transportation and installation of equipment, late ordering and poor logistics. The proposed minimization strategies are timely ordering, logistic planning and work structuring.

Bad materials or products: it stems from inexperienced supply and purchase manager; poor communication; late involvement of suppliers; and poor inspection. The proposed strategies for minimization are requisite and experienced supply/purchase manager, partnering and adequate inspection.

Ordering problems: they occur from ordering that do not fulfill design, lack of possibilities to order small quantities, wrong ordering by estimators and lack of coordination of purchase/supply. The proposed strategy is appropriate ordering.

\subsubsection{Handling FMWM}

Figure 6 presents the handling waste origins, which include unpacked supplies waste, imperfect planning, double handling and storage problems. Unpacked supplies: waste occurs through throwaway packaging. The proposed strategies for minimization in the framework are good delivery methods, programmed ordering and central dump.

Imperfect planning: it stems from unfriendly attitude from personnel, insufficient crew of workers and poor resource allocation. The proposed strategies are mechanization, increment of crews, training of operatives, multi-skilled operatives and good resource allocation.

Double handling: it occurs from wrong equipment, wrong discharge point of materials, site layouts' problems and wrong distribution of materials within site. The proposed strategies are discharge of materials at the point of usage, good site layout and good distribution method within sites.

Storage problem: it occurs from too much material inventory, inappropriate storage and congestion. The proposed strategies are appropriate storage, adequate protection for materials, just in time delivery, suppliermanaged store and off-site construction.

\subsubsection{Operation FMWM}

The origins of operation waste presented in Figure 7 are inexperience, delay, damages, errors and wrong methods. Inexperience: it stems from inexperienced inspectors, unskillful subcontractors, unskillful tradesmen, poor site layout and setting out, poor supervision, low quality target and unqualified personnel. The proposed strategies for minimization include training, competent and skillful personnel, and adequate supervision.

Delay: it occurs from equipment malfunctions/ shortage; inclement weather; late information; unnecessary people moves; lack of top management support; and theft. The proposed strategies are top management support, security, good program of work, good planning and good equipment.
Damages: it occurs due to subsequent trades and accidents. The proposed strategies for minimization are total quality management and introduction of safety policies. Errors: they result from workers' mistakes, poor workmanship, inappropriate/ misuse of materials, misinterpretation of drawings, replacement occasioned by wrong materials, conversion and negligence. The proposed strategies for minimization are multi-skilled operatives, last planner, off site construction, first run studies and visual management.

Wrong methods: these are due to too much overtime for labour; poor formwork; improper planning and organizations; improper sites' records; poor material management practices; non-usage of modern methods; and lack of waste management plan. The proposed minimization strategies are benchmarking, value-based management, re-engineering, modern methods, steel formwork, corrective actions and sub-contractors managing waste generated by them.

\subsection{Frameworks'validation.}

\subsubsection{Aim and objectives of the validation}

The aim of the validation is to refine and assess the content and appropriateness of the proposed FMWM for medium and large contracting organizations.

The objectives of the validation are: -

1. To assess the clarity of the proposed FMWM.

2. To examine the information flow of the proposed FMWM.

3. To ascertain the appropriateness of the content and structure of the five subsidiary-level FMWM.

4. To examine the comprehensiveness of the content of the proposed FMWM

5. To identify other waste routes, waste origins and minimization strategies that may not be contained in the proposed FMWM.

6. To identify potential implementation strategies for the proposed FMWM.

7. To find out the overall assessment and applicability of the proposed FMWM.

The validation was done in two stages, which are pilot validation and main validation.

\subsubsection{Pilot Validation}

Eleven academics in the University of Lagos were contacted to modify the framework out of which five of them participated. It involved them rigorously criticizing the proposed FMWM and also evaluate them via an instrument. The five researchers include a Professor, an Associate Professor, two Senior Lecturers and a Lecturer II of the University of Lagos, Nigeria. All of them hold $\mathrm{PhD}$ degree and their academic/research experiences range between six to over 20 years. Four of them either "agree" or "strongly agree" with the clarity of the mainlevel FMWM in terms of structure, content and process. Similarly, three of them either "agree" or "strongly agree" with the information flow of the main-level FMWM in terms of clarity and relationships. One each "disagree" and "neither agree/ disagree". Additionally, four of them either "agree" or "strongly agree" with the appropriateness of the five subsidiary- level FMWM in terms of clarity, familiarity and content. Again, one of 
them "disagree". The opinion of the one person who disagreed was sought on improvement. His comment was that the arrow showing relationship should be improved to enhance understanding and interpretation of the frameworks. All the comments and suggestions of the academics were employed in the improvement of the proposed FMWM. One of them also commented that some of the minimization strategies (especially, lean construction techniques) should be explained in the proposed FMWM for the benefit of those who do not know them. All their suggestions were used to modify the proposed FMWM. Consequently, the proposed FMWM were sent to 25 potential end users (five each from the five categories of end users indicated earlier) with an evaluation instrument, out of which 17 were returned and found useful. The suggested measures from the pilot survey, which were used to improve the proposed FMWM prior to the main validation, are presented in Table 3.

Table 3: Improvement measures suggested from the pilot study and modification actions taken on the framework.

\begin{tabular}{|c|c|c|}
\hline $\mathbf{S} / \mathbf{N}$ & Proposed Improvement Measures & Modification Actions Taken \\
\hline 1. & $\begin{array}{l}\begin{array}{l}\text { Minimize the complexity } \\
\text { of arising from } \\
\text { multiplicity } \\
\text { elements/components. }\end{array} \\
\text { redundant }\end{array}$ & Removal of redundant boxes. \\
\hline 2. & $\begin{array}{l}\text { Additional indicative arrows to convey } \\
\text { messages convincingly. }\end{array}$ & $\begin{array}{l}\text { Introduction of arrows from waste quantification to } \\
\text { strategies for waste minimization. }\end{array}$ \\
\hline 3. & $\begin{array}{l}\text { Sequential arrangement of origins of waste } \\
\text { under some sources of waste in the main-level } \\
\text { framework. }\end{array}$ & $\begin{array}{l}\text { Rearrangement of the design origins of waste in the main- } \\
\text { level framework - design changes, uncollaboration, } \\
\text { inconsideration for standard sizes were rearranged as } \\
\text { inconsideration for standard sizes, uncollaboration, design } \\
\text { changes. }\end{array}$ \\
\hline 4. & Rework some of the content. & Uncollaboration was changed to lack of collaboration, \\
\hline 5. & Inclusion of lean construction techniques & $\begin{array}{l}\text { Additional lean construction techniques were included, with } \\
\text { an instruction to investigate and embed relevant lean } \\
\text { techniques in all the boxes for strategies for waste } \\
\text { minimization. }\end{array}$ \\
\hline
\end{tabular}

Explanation of some minimization strategies

6. that may not be known to the respondents especially the lean construction techniques
Explanation of about 21 strategies is included as footnotes on the framework.

\subsubsection{Main validation.}

4.5.3.1. Demographic information of respondents

Table 4 shows the demographic information of the respondents that participated in the validation exercise. A total of 17 construction professionals were involved in the exercise out of the 25 that were contacted. $23 \%$ of them are project managers, $18 \%$ each are builders and architects while $35 \%$ and $6 \%$ are civil engineers and quantity surveyors respectively. Also, 64\% have M.Sc degree, while $18 \%$ each has B.Sc degree and HND. $18 \%$ have less than 5 years construction experience, $29 \%$ have from 6 to 10 years and 53\% have from 11 to 15 years.

Table 4: Demographic information of respondents

\begin{tabular}{lcc}
\hline Respondents' information & Frequency & Percentage \\
\hline Designation & 4 & 23 \\
\hline Project Managers & 3 & 18 \\
Builders & 3 & 18 \\
Architects & 6 & 35 \\
Civil Engineers & 1 & 6 \\
Quantity Surveyors & & \\
\hline Profession & 3 & 18 \\
\hline Architecture & 2 & 12 \\
Quantity Surveying & 4 & 24 \\
Building & 8 & 47 \\
Civil Engineering & & \\
\hline Academic qualification & 11 & 64 \\
\hline M.Sc & 3 & 18 \\
B.Sc & 3 & 18 \\
HND & &
\end{tabular}

\section{Construction experience}

\begin{tabular}{lcc}
\hline Less than 5 years & 3 & 53 \\
$6-10$ years & 5 & 29 \\
$11-15$ years & 9 & 53 \\
\hline Category of organization & & \\
\hline Indigenous & 12 & 71 \\
Multinational & 5 & 29 \\
\hline Type of organization & & \\
\hline Private & 11 & 65 \\
Public & 6 & 35 \\
\hline Nature of organization & & \\
\hline Contracting & 11 & 64 \\
Consulting & 3 & 18 \\
Client & 3 & 18 \\
\hline
\end{tabular}

Moreover, $71 \%$ of the respondents are from indigenous construction organization while $29 \%$ are from multinational organization, $65 \%$ are from private organizations while $35 \%$ are from public. Also, $64 \%$ are from contracting organizations, $18 \%$ each from consulting and client organizations. The result shows that the targeted respondents are qualified to validate the proposed frameworks.

\subsubsection{Clarity of the main-level FMWM}

The respondents were asked to rate their agreement level (from strongly disagree to strongly agree) about the statements on clarity provided in the questionnaire. The result reveals that $94 \%$ of them either "agree" or "strongly agree" with the clarity of the framework in terms of structure, content, sources and causes of waste within the material waste minimization process in the main-level. 
Only 6\% "nether agree/disagree" just on familiarity with the content alone.

4.5.3.3. Information flow of the main-level FMWM

The respondents were asked to rate their agreement level (from strongly disagree to strongly agree) about the statements on information flow of the main-level FMWM provided in the questionnaire. The result reveals that at least $75 \%$ of the respondents either "agree" or strongly agree" with the information flow of the framework, in terms of clarity and relationship between the sources and causes of waste, and material waste minimization process in the main component.

\subsubsection{Appropriateness of the Subsidiary-level FMWM} clusters.

The respondents were also asked to indicate the appropriateness of the five subsidiary-level FMWM (from strongly disagree to strongly agree) on the statements provided in the questionnaire. The result sheds light that at least $75 \%$ of the respondents either "agree" or "strongly agree" with the five subsidiary components in terms of structures' clarity, contents' familiarity, contents' appropriateness and clarity of material waste minimization process.

\subsubsection{Overall assessment and applicability of the FMWM}

The respondents were asked to rate some framework assessment and applicability statements (FAAS), from extremely poor (1) to excellent (5), to indicate the overall assessment and applicability of the entire framework. The result is shown in Table 5. Interestingly, the result shows that all the respondents (i.e. 100\%) either indicated "above average" or "excellent" for the assessment and applicability of the framework. Infact, $65 \%$ opined "excellent" on the comprehensiveness and practical relevance to material waste minimization, while over $75 \%$ also indicated "excellent" on the applicability in minimizing materials wastage.

\subsection{Implementation Strategies of the FMWM}

The following implementation strategies were suggested by various respondents:

1. Engagement of competent and requisite professionals for site works.

2. There is the need for usage of skillful workers.

3. Proper monitoring and coordination of material procurement.

4. Training and education on movement and storage of materials.

5. There is the need to allow suppliers to manage storage of materials.

6. Adequate planning for handling and good materials packaging.

7. Teamwork.

8. Educating workers on correct placement of materials.

9. Good material packaging and changing construction methods.

10. Mechanization or increasing crew on sites.

11. Total quality management.

12. Achievable objectives must be clearly stated for achievable goals.
13. Usage of waste audit.

The Nigerian building industry requires frameworks to forestall the incidence of material waste on building projects. Previous works on the issue of waste in Nigeria have not attempted to evolve a framework that can be used by construction practitioners to prevent and reduce material waste. Additionally, Wahab and Lawal (2011) indicate that there are no policies that mandate contractors to minimize material waste on projects. The introduction of policies will not be efficient, if there are no frameworks that synergize the key issues about waste, especially as it relates to the Nigerian context. The proposed FMWM in this study depicts factors that are germane to waste incidence and processes for their minimization. A major highlight in the framework for waste minimization apart from identifying routes of waste and minimization strategies is the analysis and evaluation of waste. This is seldom practiced in Nigeria. For instance, designs are not evaluated for waste in Nigeria. Thus, a lot of waste that could be prevented at the design stage occurs on site. Ekanayake and Ofori (2004) developed and recommended Building Waste Assessment Score (BWAS) model to evaluate designs for potential to generate waste, so as to produce designs that have less potential to generate waste. Contractors are also enjoined to employ the model to select site management techniques which help them to face the waste challenge posed by the design. Designs should also be subjected to 'buildability and maintainability analysis', which will reveal among other things, the inherent waste tendency in designs. Moreover, the frameworks suggest that clients need to be educated on the implication of their undue involvement in building projects. Additionally, a major advocate in the frameworks is the application of Lean Construction (LC) techniques in building projects in Nigeria. Polat and Ballard (2005) recommend the application of tools and techniques of LC to prevent waste from occurring by identifying the root-causes of waste and eliminating them at all stages of construction. However, Oladiran (2008b) reveals that LC is alien to the Nigerian building industry; while the study also indicates the barriers and implementation strategies for LC in Nigeria, of which is education and skill development on LC. Thus, there has been growing interest, research and development on LC in Nigeria; hence its inclusion in the frameworks. Furthermore, the validation exercise reinforces the need, relevance and appropriateness of the frameworks. The validation exercise highlights various implementation strategies for them. The practical relevance of the framework can be seen in the evaluation and comments of the potential end users. The following comments were made on the frameworks by some of the respondents:

i. If the frameworks are fully implemented on site, waste will be minimized on construction sites.

ii. The frameworks are implementable on construction sites and must be effectively practiced.

iii. They are good frameworks.

iv. The information and the flow is self explanatory.

v. There is thorough research and comprehensive details about the framework. The report surely is understandable and obtainable.

vi. They are satisfactory. 


\section{Conclusion and Recommendations}

The study opined that frameworks that can be used to minimize material wastage on projects do not exist in Nigeria. This gap was filled by the frameworks provided in the study. The frameworks can be used to minimize material waste at every stage of building projects. They suggest that material waste minimization does not start from the sites, but from the clients to everyone involved in the execution of building projects. Thus, all stakeholders need an understanding of the issues, content and processes of the framework for effective minimization of material wastage. The study recommends that the proposed FMWM should be adopted by all stakeholders to minimize material waste at all stages of building projects. It should also be adopted to formulate

\section{References}

Adewuyi, T.O., \& Otali, M. (2013). Evaluation of causes of construction material waste -- case of Rivers State, Nigeria. Ethiopian Journal of Environmental Studies and Management, 6: $746-753$.

Akande, O.A. (2000). Estimating the percentage wastage of materials in tendering- case of concretework and blockwork. (M.Sc project report). University of Lagos, Yaba, Lagos, Nigeria.

Akinkurolere, O.O. \& Franklin, S.O. (2005), Investigation into Waste Management on Construction Sites in South Western Nigeria. American Journal of Applied Sciences 2 (5): 980-984.

Al-Moghany, S.S. (2006). Managing and minimizing construction waste in Gaza Strip. (M.Sc project report). Islamic University of Gaza - Palestine.

Awodele, O.A. (2012). Framework for managing risk in privately financed market projects in Nigeria. (Doctorate Thesis), Heriot-Watt University.

Centre for Research in the Built Environment (CRiBE) (2003). Construction waste minimization - Good Practice Guide."

Chew, J. \& Sullivan, C. (2000). Verification, validation, and accreditation in the life cycle of models and simulations. In: Awodele, O.A. (2012). Framework for managing risk in privately financed market projects in Nigeria. (Doctorate Thesis), Heriot-Watt University.

Dajadian, A.D. \& Koch, D.C. (2014). Waste management models and their applications on construction sites. International Journal of Construction Engineering and Management, 3(3), 91-98.

Edwards, B. (1999). Sustainable architecture: European directives and building design. 2nd ed., Oxford: Architectural Press.

Ekanayake, L.L., \& Ofori, G. (2000). Construction material waste source evaluation. Proceedings from 2 nd Southern African conference on sustainable development in the built environment: strategies for a sustainable built environment, Pretoria, South Africa, August 23 -25: 1 6.

Enshassi, A. (1996). Materials control and waste on building sites. Building Research Information, 24(1), 3134. policies for waste minimization. Practitioners should be sensitized to the potential gains of the proposed framework to minimize material wastage.

\section{Further Area of Research}

The proposed frameworks were validated using face validity and scoring model approaches as suggested and used in previous works (Sargent, 2005; Awodele, 2012; Gamage, 2011). It is important to validate them on real life projects for improved objective assessment. Future research will therefore focus on validating the frameworks on case projects to further ascertain its applicability and effectiveness.

Ekanayake, L. L., \& Ofori, G. (2004). Building waste assessment score: design-based tool. Building and Environment, 39: 851-861.

Fuchs, R. (2003). Avoiding construction waste. New Zealand: Building Biology and Ecology Institute.

Formoso, C. T., Isatto, E. L., \& Hirota, E. H. (1999). Method for waste control in the building industry. Proceedings of International Group for Lean Construction - 7, University of California, Berkeley, CA, USA, July 26 $-28,325-334$.

Gamage, I.S.W. (2011). A waste minimization framework for the procurement of design and build construction projects. (Doctorate Thesis), Loughborough University.

Li, Zhang, Ding \& Feng (2015). Developing a quantitative construction waste estimation model forbuilding construction projects. Resources, Conservation and Recycling, 106 (2016) 9-20.

Lu, W. \& Yuan, H. (2011). A framework for understanding waste management studies in construction. Waste Management, 31 (6), 1252-1260.

Manowong, E \& Brockmann, C. (nd). Construction Waste Management in Newly industrialized countries. Retrieved on 26/07/2108 from: https://www.irbnet.de/daten/iconda/CIB_DC24555.pdf

Motete, L., Mbachu, J., \& Nkado, R. (2003). Investigations into material wastage on building sites. Proceedings of CIDB 1st postgraduate conference, Port Elizabeth, South Africa, October 14, 1-10.

Ng, L. S., Seow, T. W. \& Goh, K. C. (2015). Implementation on solid waste reduction through $3 \mathrm{R}$ (NSWM Policy) and elements to close gap between policy and contractors in construction industry in Penang. International Journal of Environmental Science and Development, 6(9), $668-675$.

Oladiran, O.J. (2008a). Optimization of waste management plan for waste reduction on construction projects in Nigeria. Proceedings: International conference on innovation in Architecture, Engineering and construction, June 23-25, Antalya, Turkey.

Oladiran, O. J. (2008b). Lean -In- Nigerian Construction: State, Barriers, Strategies and "Go-ToGemba" Approach. Proceedings of the IGLC -16 , Manchester, UK.. 
Otunola, A.T. (2004). The use of waste recycled materials in the construction industry. (Unpublished M.Sc project report). University of Lagos, Yaba, Lagos, Nigeria.

Poon, C. S., Yu, A. T. W., Wong, S. W., \& Cheung, E. (2004). Management of construction waste in public housing projects in Hong Kong. Construction Management and Economics, 22(7): 675-689.

Polat, G ., \& Ballard, G . (2005). Waste in Turkish construction: Need for Lean Construction techniques. Proceedings of International Group for Lean Construction - 13, Sydney, Australia, July 18 - 20, $1-14$.

Proverbs, D. , \& Olomolaye, P. (1995). Organizational Productivity - A case study of materials management in UK construction firms. Proceeding of 1st International Conference on Construction project management, Singapore, January.

Recycling Council of Ontario (RCO) (2009). 3Rs for construction and demolition projects. Ontario: Queen's Printer

Sargent R. G. (2005). Verification and validation of simulation models. In: Awodele, O.A. (2012). Framework for managing risk in privately financed market projects in Nigeria. (Doctorate Thesis), Heriot-Watt University.

Seydel, A. Wilson O. D. , \& Skitmore, R. M.(2002). Financial evaluation of waste management methods. Journal of Construction Research, 3(1): 161-167.

Skoyles, E.R.,\& Skoyles, J.R. (1987). Waste prevention on site. London: Mitchell Publishing.

Straker, D.1 (995). A tool book for quality improvement and problem solving. London: Prentice Hall.

Tam, V.W.Y. \& Tam, C.M. (2006). Evaluations of existing waste recycling methods: A Hong Kong study. Building and Environment, 41(12), 1649-1660.

Tam, V.W.Y. \& Tam, C.M. (1994). A Review on the Viable Technology for Construction Waste Recycling. Proceedings of the first international conference of CIB TG 16 , Centre for Construction and Environment, Ganiesville, Florida

Wahab, A.B., \& Lawal, A.F. (2011). An evaluation of waste control measures in construction industry in Nigeria. African Journal of Environmental Science \& Technology, 5(3), $246-254$. 